\title{
REFLETÂNCIA ESPECTRAL DE FOLHAS VERDES DA CANA-DE- AÇÚCAR EM FUNÇÃO DO SEU ESTADO NUTRICIONAL EM NITROGÊNIO.
}

\author{
Henrique C.J. Franco (PQ), Sérgio G.Q. de Castro (PG), Gabriel D.A.C. de Moraes (IC)
}

\begin{abstract}
Resumo
Nesse trabalho propomos determinar a correlação entre o estado nutricional da cana soca fertilizada com diferentes doses de nitrogênio, aplicadas em diferentes épocas após a colheita, com o espectro de frequência da refletância das folhas verdes, almejando maiores produtividades e adequação da dose de $\mathrm{N}$ fertilizante a ser empregada na lavoura
\end{abstract}

Palavras Chave: Sensores, NDVI, SPAD

\section{Introdução}

Devido a expressiva produção de cana-deaçúcar, o Brasil é o quarto maior consumidor de Fertilizantes NPK (Nitrogênio-Fósforo-Potássio) no mundo (ANDA,2013), sendo assim é clara a necessidade do uso de técnicas de agricultura de precisão para o correto uso desses fertilizantes, ao passo que possa utilizar a quantidade correta em função das necessidades da planta.

Para isso, o uso do sensoriamento remoto próximo (sensores ópticos acoplados ou não a máquinas agrícolas), que parte do principio de que propriedades espectrais, reflectância e transmitância das folhas afetadas pela deficiência de $\mathrm{N}$ em todo o dossel das plantas, se apresenta com um potencial para mensurar grandes áreas, permitindo a maximização da aplicação do nitrogênio na dose adequada a necessidade das plantas

O delineamento estatístico utilizado foi em blocos casualizados em esquema fatorial $2 \times 5$ com quatro repetições, sendo duas épocas, 45 e 90 DAC (dias após o corte); cinco doses de nitrogênio (0, 50, 100, 150 e $200 \mathrm{~kg} \mathrm{ha}^{-1}$ ). O estado nutricional foi avaliado aos 45, 90, 120 e 150 dias após a instalação dos tratamentos.

\section{Resultados e Discussão}

O sensor de reflectância do dossel da cultura (ACS 430 - Crop Circle) foi capaz de mensurar diferença entre as doses de fertilizante nitrogenado, na avaliação feita aos 150 DAC, na qual as doses de nitrogênio apresentaram efeito quadrático $\quad\left(y=\quad-0,000006 x^{2}+0,0019 x+0,544\right.$ $\mathrm{R}^{2}=0,99^{* *}$ ) no índice NDVI e NDRE, com o maior valor obtido com a dose de $160 \mathrm{~kg} \mathrm{ha}^{-1}$ de $\mathrm{N}$, para ambos. Nessa mesma avaliação, o sensor de reflectância foi hábil em diferenciar as épocas de aplicação do fertilizante, na qual a aplicação feita aos 90 DAC apresentou índices superiores aos obtidos na aplicação aos 45 DAC.

O clorofilômetro (SPAD 502 Minolta) também apresentou diferença no índice SPAD segundo as doses e época de aplicação adotada. Semelhante ao sensor de dossel, a aplicação feita aos 90DAC apresentou valores superiores, e as doses de $\mathrm{N}$ apresentaram efeito quadrático no índice SPAD $\left(y=-0,0003 x^{2}+0,1078 x+40,36\right.$ $\mathrm{R}^{2}=0,99^{* *}$ ) com maior valor do índice mediante a aplicação de $180 \mathrm{~kg} \mathrm{ha}^{-1}$ de $\mathrm{N}$. Nesse sentido, o uso de sensores se torna hábil em auxiliar no manejo e aplicação do fertilizante nitrogenado na cultura da cana-de-açúcar.

A produtividade da cana-de-açúcar $(\mathrm{TCH})$, não apresentou diferença em relação às épocas de aplicação, porém o aumento da dose de $\mathrm{N}$ promoveu efeito quadrático na $\mathrm{TCH} \quad(\mathrm{y}=-$ $0,0019 x^{2}+0,5784 x+68,3 \quad R^{2}=0,89^{* *}$ ) com o maior valor obtido mediante a aplicação de $152 \mathrm{~kg} \mathrm{ha}^{-1}$ de $\mathrm{N}$.

\section{Conclusões}

O clorofilômetro e o sensor de dossel são aptos na detecção das doses e épocas de aplicação do fertilizante nitrogenado. A adubação nitrogenada em cana-de-açúcar apresenta incrementos significativos na $\mathrm{TCH}$, sendo que o maior valor é obtido com a aplicação de $152 \mathrm{~kg} \mathrm{ha}^{-1}$ de $\mathrm{N}$ independentemente da época de aplicação.

\section{Agradecimentos}

Agradeço a FEAGRI/UNICAMP, pelo conhecimento ministrado ao longo de minha graduação. Também agradeço ao CTBE-CNPEM, pela infraestrutura, e por último ao PIBIC/SAE, órgão pelo qual essa pesquisa foi fomentada.

\footnotetext{
${ }^{1}$ ANDA (Agência Nacional de Difusão de Adubos). Disponível em: www.anda.gov.br, boletim técnico 2013. Acesso em: 01 de Dez. de 2013.
} 